\title{
KEPRIBADIAN KARYAWAN DAN BUDAYA ORGANISASI: FAKTOR DETERMINAN KETERIKATAN KARYAWAN (EMPLOYEE ENGAGEMENT)
}

\author{
Rian Nurjanah, Rofi Rofaida, dan Suryana \\ Fakultas Pendidikan Ekonomi dan Bisnis, Universitas Pendidikan Indonesia \\ Email: rofirofaida@upi.edu
}

\begin{abstract}
This research based on declining sales outcome and not achieves the target, a fine delay completion of project high, and losses PT X, one of the companies in telecommunication industry at Jawa Barat in 2014. Profitability and productivity relating to employee engagement. Research aims to describe employee personality, organizational culture perception, and employee engagement and to know the influence of employee personality and organizational culture perception on employee engagement. This research is done with descriptive and verification method. This research use causality design. Statistical analysis used in this research was pearson correlations analysis and multiple regression. This research result indicates that employee personality influential positively and significant impact on employee engagement. Organizational culture perception has positive and significant impact on employee engagement too. Employee personality and organizational culture perception simultaneously and significant impact on employee engagement, but the biggest influence to employee engagement is employee personality.
\end{abstract}

Keywords: Employee Personality, Organizational Culture Perception, and Employee Engagement

Abstrak: Penelitian dilatarbelakangi oleh hasil penjualan yang menurun dan tidak memenuhi target, denda keterlambatan penyelesaian proyek yang tinggi, dan kerugian yang dialami oleh PT X, salah satu perusahaan yang bergerak pada industri telekomunikasi di Jawa Barat. pada tahun 2014. Profitabilitas dan produktivitas perusahaan berkaitan dengan keterikatan karyawan (employee engagement). Penelitian ini bertujuan untuk mengetahui gambaran kepribadian karyawan, persepsi budaya organisasi menurut karyawan, dan keterikatan karyawan serta untuk mengetahui pengaruh kepribadian karyawan dan persepsi budaya organisasi terhadap keterikatan karyawan (employee engagement). Penelitian dilakukan dengan menggunakan metode deskriptif dan verifikatif. Desain penelitian ini adalah desain kausalitas. Analisis statistik yang digunakan dalam penelitian ini adalah analisis korelasi pearson product moment dan analisis regresi berganda. Hasil penelitian ini menunjukkan bahwa kepribadian karyawan berpengaruh secara positif dan signifikan terhadap keterikatan karyawan. Demikian dengan persepsi budaya organisasi juga berpengaruh positif dan signifikan terhadap keterikatan karyawan. Kepribadian karyawan dan persepsi budaya organisasi secara simultan dan signifikan berpengaruh terhadap keterikatan karyawan, namun yang memiliki pengaruh lebih besar terhadap keterikatan karyawan adalah kepribadian karyawan.

Kata kunci: Kepribadian Karyawan, Persepsi Budaya Organisasi, dan Employee Engagement. 


\section{PENDAHULUAN}

Penelitian dilatarbelakangi oleh fenomena yang terjadi di PT X salah satu perusahaan yang bergerak pada industri telekomunikasi di Jawa Barat. pada tahun 2014. Fenomena yang terjadi yaitu hasil penjualan yang menurun sebesar 44,24\% dan pencapaian target kerja hanya sebesar 34,91\%. Penjualan yang belum memenuhi target dikarenakan penurunan produktivitas yang ditunjukkan oleh terjadinya keterlambatan penyelesaian proyek yang menimbulkan denda keterlambatan yang tinggi mencapai 7,782 miliar rupiah seperti diuraikan pada Gambar 1. Denda yang tinggi mengakibatkan Perusahaan menanggung kerugian sebesar 265,9 miliar rupiah pada tahun 2014.

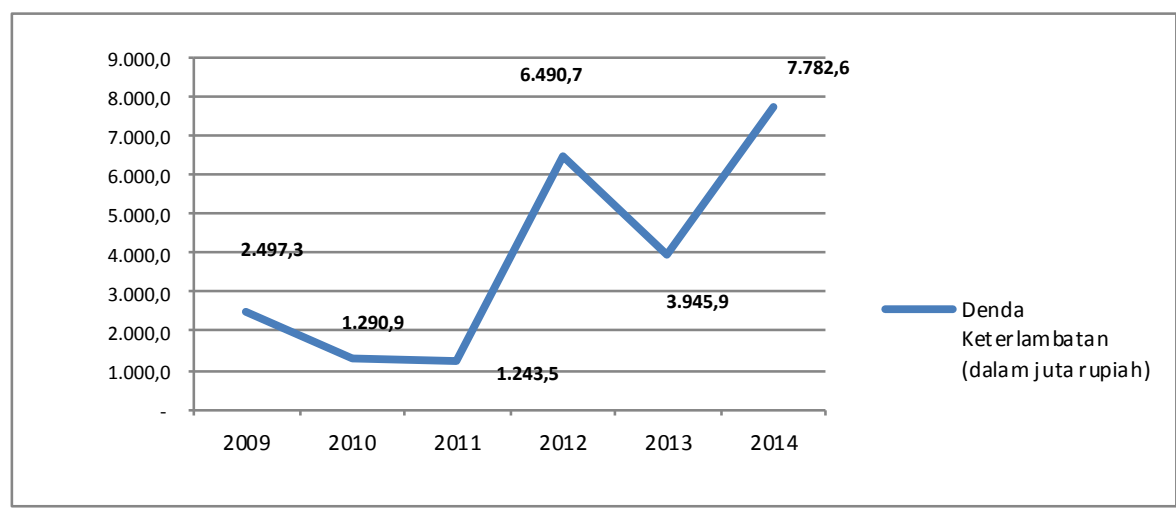

Gambar 1. Grafik Denda Keterlambatan Penyelesaian Proyek PT X

Tahun 2009-2014 (dalam juta rupiah)

Sumber: Laporan Tahunan PT X tahun 2009-2014, diolah

Fenomena di atas menjadi salah satu indikator keterikatan karyawan (employee engagement) yang rendah. Keterikatan karyawan (employee engagement) adalah pernyataan perasaan positif tertinggi dalam suatu hubungan pekerjaan dan organisasi yang ditunjukan dengan upaya ekstra dalam pekerjaan, antusias, giat, dan bergairah (Denison, D, 2011). Kepuasan/kesetiaan, profitabilitas, produktivitas, perputaran, dan hasil-hasil keselamatan kerja sangat berhubungan dengan keterikatan karyawan (Kreitner dan Kinicki, 2014). Kinerja organisasi akan berkualitas jika sumber daya manusia yang melakukan pekerjaan tersebut memiliki keterikatan (engagement) yang tinggi baik secara fisik, kognitif, maupun emosional terhadap pekerjaan dan organisasinya. Karyawan yang memiliki keterikatan tinggi terhadap pekerjaan dan organisasinya akan datang bekerja secara teratur, punya rasa memiliki terhadap organisasi, memiliki motivasi dan kinerja individu yang tinggi. Engagement karyawan dalam sebuah organisasi akan menentukan produktivitas karyawan. Kinerja individu memberikan multiplier effect terhadap kinerja perusahaan misalnya meningkatkan produktivitas, mengurangi pemborosan, dan meningkatkan keuntungan perusahaan.

Model Perilaku organisasi menggambarkan keterikatan karyawan dalam perspektif individu dan organisasi. Bahwa keterikatan karyawan merupakan fungsi dari kepribadian dan lingkungan Pada level individu terdapat input kepribadian yang dapat mempengaruhi keteriatan karyawan. Ciri-ciri kepribadian individu cenderung mempengaruhi sejauh mana pengalaman karyawan dan menunjukkan engagement karyawan di tempat kerja. Sedangkan pada level oganisasi, faktor budaya organisasi dapat menjadi faktor pendorong 
bagi keterlibatan karyaan untuk memberikan effort yang ekstra ordinary kepada organisasi. Keterikatan karyawan dapat menjadi hasil potensial dari budaya organisasi yang positif. (Robbins, Stephen P, dan Judge, Timothy, A, 2015; Albrecht, Simon L., et al, 2015; Denison, Daniel R, 2011).

Tujuan penelitian ini adalah sebagai berikut: (1) Melakukan pemetaan dan analisis secara deskriptif mengenai keterikatan karyawan (employee engagement) pada PT. X; (2) Melakukan pemetaan dan analisis secara deskriptif mengenai kepribadian karyawan pada PT. X; (3) Melakukan pemetaan dan analisis secara deskriptif mengenai penerapan budaya organisasi di PT. X; (4) Melakukan pengukuran tingkat determinasi kepribadian karyawan dan budaya organisasi terhadap keterikatan karyawan (employee engagement) baik secara parsial maupun secara simultan; (5) Memberikan rekomendasi berkaitan dengan strategi yang dapat dilakukan perusahaan untuk meningkatkan keterikatan karyawan (employee engagement)didasarkan pada hasil analisis secara empiris terhadap variabel kepribadian karyawan dan budaya organisasi

\section{KAJIAN TEORI}

Keterikatan Karyawan (employee engagement). Keterikatan Karyawan (employee engagement)digambarkan sebagai 'being fully physically, cognitively and emotionally connected with their work roles.' Keterlibatan secara fisik, kognitif dan emosi dengan pekerjaan yang menjadi tanggungjawabnya. Keterlibatan tersebut memberikan pernyataan perasaan positif tertinggi dalam suatu hubungan pekerjaan dan organisasi yang ditunjukan dengan upaya ekstra dalam pekerjaan, antusias, giat, dan bergairah. Keterlibatan juga bisa mengandung arti kepusan dan antusiasme seseorang dalam bekerja sehingga menghasilkan upaya ekstra dalam bekerja (Albrecht, Simon L., et al, 2015; Denison, Daniel R, 2011; Kreitner \& Kinicki,2014). Keterikatan karyawan merupakan upaya mengarahkan seluruh energi yang dimiliki karyawan yang dilakukan secara terus menerus, konsisten, dan diarahkan bagi pencapaian tujuan organisasi. Engagement is an individual's sense of purpose and focused energy, evident to others in the display of personal initiative, adaptability, effort, and persistence directed toward organizational Goals (Albrecht, Simon L., et al, 2015)

Schaufeli W.B., Bakker A.B., dan Salanova M. (2010) mengemukakan engagement sebagai, "a positive, fulfilling, work-related state of mind that is characterized by vigor, dedication, and absorption.” Dalam definisi ini, engagement merupakan keadaan pikiran yang positif mengenai pekerjaan, yang dicirikan oleh semangat, dedikasi, dan absorpsi. Diuraikan tingkatan employee engagement yang dikemukakan Schaufeli \& Bakker (2010:13) yaitu sebagai berikut: (1) Vigor (semangat). Vigor mengacu pada kemauan dan tekad untuk mengerahkan energi dan usaha dalam pekerjaan dan menjadi ulet serta gigih ketika menghadapi rintangan.; (2) Dedication (dedikasi). Dedikasi mengacu pada keterlibatan dalam pekerjaan yang ditengarai oleh perasaan bermakna, semangat, inspirasi, bangga, dan tantangan di tempat kerja; (3) Absorption (absorpsi). Absorpsi menunjukan bahwa karyawan begitu berkonsentrasi, bahagia, dan sepenuhnya terserap dalam pekerjaannya sehingga waktu berlalu begitu cepat dan karyawan sulit memisahkan dirinya dari pekerjaannya.

Kepribadian Karyawan. Robbins, Stephen P, dan Judge, Timothy, A, (2015) mengemukakan bahwa Personality is the dynamic organization within the individual of 
those psychophysical systems that determine his unique adjustment to his environment. Personality defined as the sum total of ways in which an individual react and interacts with others, the measurable traits a person exhibits. Kepribadian adalah organisasi yang dinamis dari sistem psikofisik individu yang menentukan cara individu tersebut menyesuaikan diri dengan lingkungannya. Keseluruhan cara individu bereaksi dan berinteraksi dengan orang lain akan membedakan individu tersebut dengan individu yang lain. Kepribadian tersebut merupakan pola tertentu dari tingkah laku dan pikiran individu yang berlaku sepanjang waktu dan bagaimanapun keadaannya yang membedakan seseorang dari orang lain. (Team FME, 2015:7).

Dalam konteks organisasi kepribadian adalah kombinasi karakteristik fisik dan mental yang relarif stabil yang memberikan identitas kepada individu. Karakteristik atau sifat ini termasuk penampilan, pemikiran, tindakan, dan perasaan seseorang sebagai hasil dari pengaruh genetik dan lingkungan yang saling berinteraksi (Kreitner \& Kinicki,2014). Engagement terjadi jika pekerjaan yang dilakukan sesuai dengan nilai-nilai pribadi, minat, kemampuan, dan kepribadian karyawan. Pada level individu terdapat input kepribadian yang dapat mempengaruhi keteriatan karyawan. Ciri-ciri kepribadian individu cenderung mempengaruhi sejauh mana pengalaman karyawan dan menunjukkan engagement karyawan di tempat kerja

Faktor-faktor kepribadian lima besar menurut Robbins, Stephen P, dan Judge, Timothy, A, (2015) sebagai hasil adaptasi dari teori The Big Five Personality McCrae \& John terdiri dari: (1) Ekstraversi (extraversion), dimensi yang menampilkan level kenyamanan karyawan di dalam hubungan. Orang yang berskor positif pada dimensi ini memiliki sifat: ekstovert, memulai percakapan, senang bergaul, suka berbicara, mempunyai banyak energi, tegas, ekspresif, percaya diri, dan mudah bersosialisasi. Kebalikannya adalah introvert yang cenderung pemalu, penakut, dan tenang. Extraversion berhubungan positif dengan engagement karena individu yang memiliki skor ekstraversi yang tinggi secara positif cenderung untuk mengalami aktivasi, kewaspadaan, dan antusiasme (Inceoglu, Ileke dan Warr, Petter, 2012); (2) Keramahan (agreeableness), imensi yang merujuk pada kecenderungan seorang individu untuk memahami orang lain. Orang yang berskor positif pada keramahan mudah percaya, bersifat baik, suka menolong, peduli, kooperatif, berhati lembut. Orang yang berskor rendah dingin, tidak ramah, dan antagonis. Keramahan secara positif terkait dengan engagement karena karyawan yang memiliki skor keramahan yang tinggi lebih mampu "memobilisasi dukungan sosial dan sumber daya untuk terlibat lebih langsung dalam peran pekerjaan mereka dan konteks organisasi" (Wildermuth, Cris, 2005). Orang-orang ramah berkontribusi pada kinerja organisasi dengan engage dalam perilaku dan tidak akan terlibat dalam penyimpangan organisasi. Karyawan dengan keramahan tinggi lebih termotivasi untuk menyelesaikan masalah dan konflik sehingga lebih terlibat dengan pekerjaan mereka (Robbins, Stephen P, Judge, Timothy, A, 2015 ; Ongore,Ozgur, 2014); (3) Kehati-hatian (conscientiousness), yaitu dimensi dimensi yang menunjukkan sebuah ukuran reabilitas. Mereka yang berskor positif pada dimensi ini dapat diandalkan, teratur, bertanggung jawab, berorientasi pada pencapaian, dan tekun. Sebaliknya, yang berskor rendah mudah dialihkan, tidak teratur, dan tidak dapat diandalkan. Conscientiousness berhubungan positif dengan engagement" (Inceoglu, Ileke dan Warr, Petter, 2012). Individu yang teliti memiliki rasa tanggung jawab dan lebih mungkin untuk melibatkan diri dalam tugas-tugas pekerjaan mereka; (4) Stabilitas emosional (emotional stability), yaitu dimensi yang menunjukkan kemampuan seseorang untuk menghadapi stress. Orang yang berskor positif cenderung tenang/relaks, 
tidak mudah khawatir, optimis, dan aman. Mereka dengan skor negatif tinggi (neuroticism) cenderung gugup, cemas, depresi, dan tidak aman. Neuroticism berhubungan negatif dengan employee engagement karena dengan mudah khawatir lebih mungkin untuk memahami lingkungan kerja mereka sebagai ancaman, kurang aman, dan menguras emosional mereka; (5) Keterbukaan pada pengalaman (openness to experience), yaitu dimensi yang mencakup kisaran minat dan ketertarikan atas inovasi. Orang yang sangat terbuka kreatif, ingin tahu, inovatif, intelek, imajinatif, berpikiran luas dan secara artistik sensitif. Sebaliknya, mereka yang berskor negatif, konvensional dan merasa nyaman dalam keadaan yang dikenal. Keterbukaan terhadap pengalaman secara positif terkait dengan employee engagement karena dengan keterbukaan terhadap pengalaman lebih mungkin untuk menjadi inovatif dan terbuka untuk perubahan (Markos, Solomon dan Sridevi, M Sandhya, 2010).

Simon L. Albrecht (2010) dalam Kaswan (2015:177) mengemukakan engagement terjadi jika pekerjaan yang dilakukan sesuai dengan nilai-nilai pribadi, minat, kemampuan, dan kepribadian karyawan. Pada level individu terdapat input kepribadian yang dapat mempengaruhi keteriatan karyawan. Ciri-ciri kepribadian individu cenderung mempengaruhi sejauh mana pengalaman karyawan dan menunjukkan engagement karyawan di tempat kerja

Budaya Organisasi. Budaya organisasi didefinisikan oleh Robbins, Stephen P, Judge, Timothy, A, (2015) sebagai : Organizational culture refers to a system of shared meaning held by members that distinguishes the organization from other organizations. Budaya organisasi mengacu pada suatu sistem berbagi arti yang dilakukan oleh para anggota yang membedakan organisasi dari organisasi lainnya. Denison, Daniel R (2011) mendefinisikan budaya organisasi sebagai : Organizational culture includes the values, beliefs, and assumptions that are held by the members of an organization and which facilitate shared meaning and guide behavior at varying levels of awareness. Budaya organisasi meliputi nilai, keyakinan, dan asumsi yang dimiliki oleh seluruh anggota organisasi dan yang memfasilitasi mereka untuk berbagi dan mengarahkan perilaku.

Tujuh karakteristik utama yang dapat menangkap intisari dari budaya organisasi adalah menurut Robbins, Stephen P, dan Judge, Timothy, A (2015) adalah sebagai berikut: (1) Inovasi dan pengambilan risiko. Tingkat para pekerja didorong untuk menjadi inovatif dan mengambil risiko; (2) Memperhatikan detail. Tingkat para pekerja diharapkan untuk menunjukkan presisi, analisis, dan memperhatikan detail; (3) Orientasi pada hasil. Tingkat manajemen menitikberatkan pada perolehan atau hasil dan bukan pada teknik dan proses yang digunakan untuk mencapainya; (4) Orientasi pada orang. Tingkat pengambilan keputusan oleh manajemen dengan mempertimbangkan efek dari hasil terhadap orangorang di dalam organisasi. Sejauh mana perusahaan menghargai hak-hak orang, memperlakukan karyawan dengan adil, dan mempercayainya; (5) Orientasi pada tim. Tingkat aktivitas kerja diorganisir dalam tim daripada individu. Orientasi pada tim dapat berupa dorongan perusahaan untuk kerjasama tim internal perusahaan dan kerjasama tim eksternal yaitu perluasan jaringan kerja (networking); (6) Keagresifan. Tingkat orangorang akan menjadi agresif dan kompetitif dan bukannya santai; (7) Stabilitas. Tingkat aktivitas organisasional menekankan pada mempertahankan status quo yang kontras dengan pertumbuhan. Pada karakteristik ini perusahaan menuntut lingkungan yang stabil dan berorientasi pada aturan-aturan. 
Budaya organisasi menentukan keterikatan karyawan pada dua tingkatan: (a) bahwa budaya menciptakan dan melepaskan energi karyawan melalui cara organisasi memperlakukan karyawannya, dan (b) bahwa budaya menyalurkan energi pada daya saing melalui pemusatan terhadap sasaran strategis perusahaan, inovasi, dan/atau efisiensi operasional (Suharti \& Suliyanto, 2012). Employee engagement dapat menjadi hasil potensial dari budaya organisasi yang positif. Budaya organisasi yang mendukung standar etika mendorong sumber daya manusia untuk mengambil risiko dan berinovasi, dan dibimbing untuk memperhatikan bukan hanya apakah tujuan yang akan dicapai melainkan juga bagaimana. Budaya organisasi yang positif menekankan pada membangun kekuatan pekerja, memberikan imbalan yang lebih sering daripada memberikan hukuman, serta menekankan pada vitalitas dan pertumbuhan dari pekerja sehingga akan menumbuhkan keterikatan karyawan Keseluruhan persepsi ini merupakan persepsi budaya organsiasi yang akan memengaruhi kinerja dan kepuasan kerja (sikap kerja), dan budaya yang lebih kuat akan memiliki dampak yang lebih besar (Parent, J. D., \& Lovelace, K. J., 2015; Naidoo, Pervashnee \& Martins, Nico,2014; Suharti \& Suliyanto,2012).

Berdasarkan uraian kajian teori, dapat disimpulkan suatu paradigma penelitian berikut:

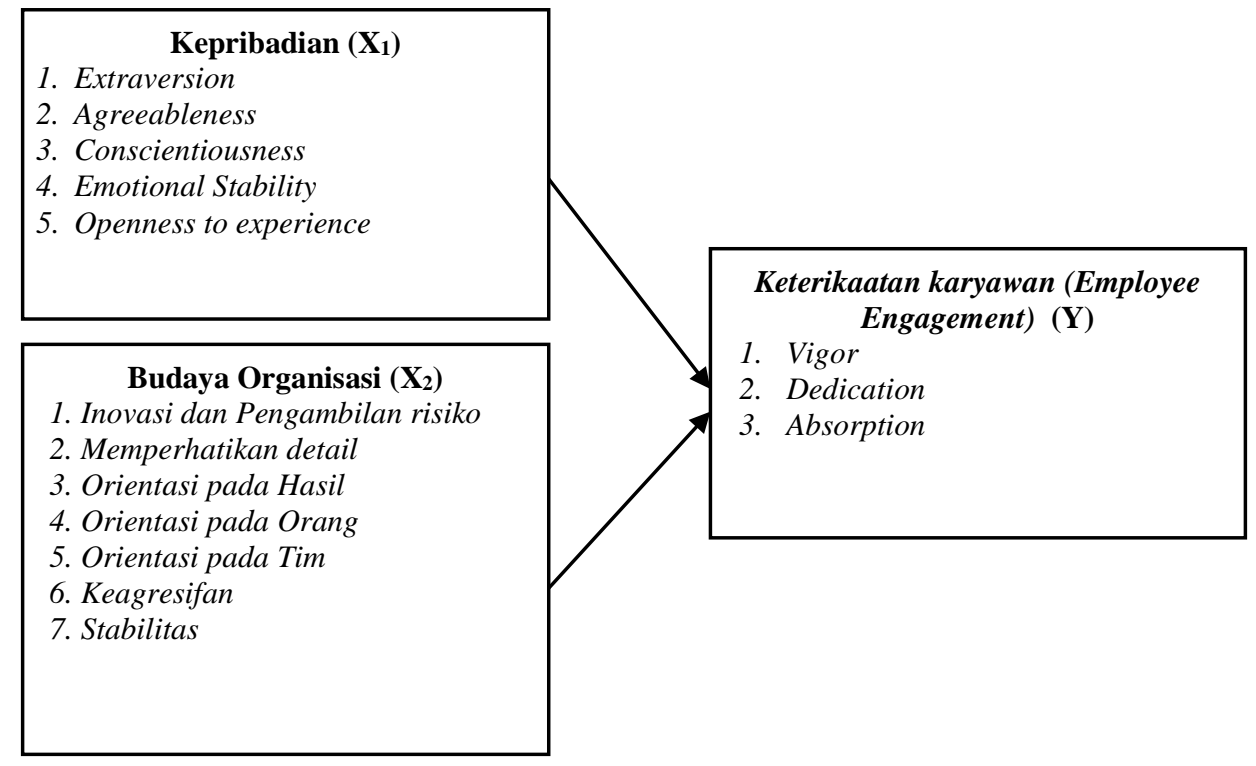

Gambar 2. Paradigma Penelitian

Berdasarkan paradigma penelitian, diajukan hipotesis penelitian sebagai berikut: (1) Terdapat pengaruh kepribadian karyawan dan persepsi budaya organisasi terhadap keterikatan karyawan (employee engagement); (2) Terdapat pengaruh kepribadian karyawan terhadap keterikatan karyawan (employee engagement);(3) Terdapat pengaruh persepsi budaya organisasi terhadap keterikatan karyawan (employee engagement).

\section{METODE}

Metode penelitian pada dasarnya merupakan cara ilmiah untuk mendapatkan informasi dengan tujuan dan kegunaan tertentu. Merujuk pada tujuan penelitian, yaitu untuk memperoleh gambaran atau deskripsi dari variabel yang diteliti serta mengungkap keterkaitan antar variabelnya maka rancangan penelitian ini menggunakan rancangan 
penelitian konklusive. Menurut Malhotra (2012) conclusive research is to test specifics hypothesis and examine specifie relationship. Suatu rancangan penelitian yang bertujuan untuk menguji hipotesis dan mengetahui hubungan antar variabel. Rancangan penelitian Konklusive terdiri dari deskriptif dan atau kausalitas.

Berdasarkan jenis penelitian deskriptif dan verifikatif, maka metode penelitian yang digunakan adalah metode descriptive survey dan metode explanatory survey untuk menjelaskan hubungan antara variabel-variabel melalui pengujian hipotesis di lapangan. Penelitian yang menggunakan descriptive survey dan metode explanatory survey dilakukan melalui kegiatan pengumpulan informasi dari sebagian populasi secara langsung di tempat kejadian (empirik) melalui alat kuesioner dengan tujuan untuk mengetahui pendapat dari sebagian populasi yang diteliti terhadap permasalahan penelitian. Lewat penelitian deskriptif ini maka dapat diperoleh gambaran mengenai kepribadian karyawan, persepsi budaya organisasi menurut karyawan, dan employee engagement pada PT. X. Sementara itu, metode penelitian verifikatif untuk mengetahui pengaruh antara variabel Kepribadian dan Persepsi Budaya Organisasi terhadap variabel Employee Engagement yang dilakukan melalui pengumpulan data di X. Kuesioner yang digunakan dalam penelitian ini adalah kuesioner kepribadian lima besar dan kuesioner budaya organisasi dari Robbins, Stephen P, dan Judge, Timothy, A, (2015) yang diolah sesuai objek penelitian, serta kuesioner keterikatan karyawa yang adaptasi dari kuesioner baku Schaufeli W.B., Bakker A.B., dan Salanova M. (2010).

Populasi penelitian ini berjumlah 592 orang yang terdiri dari 43 orang Kepala Bagian, 125 orang Kepala Urusan, dan 424 orang Staff. Berdasarkan rumus Slovin dengan presentase kelonggaran ketidaktelitian 10\% diperoleh sampel sebanyak 90 orang. Pengambilan sampel dilakukan dengan metode Proportionate Stratified Random Sampling yaitu pengambilan sampel dari anggota populasi secara acak dan berstrata secara proporsional. Teknik ini digunakan karena populasi tersebar dalam beberapa kelompok. Dihasilkan proporsi sampel dari tiap jabatan adalah : kepala bagian sebanyak 7 orang, kepala urusan sebanyak 19 orang, dan staff sebanyak 64 orang.

Pengujian hipotesis bertujuan untuk mengetahui apakah terdapat pengaruh yang signifikan dari variabel independen terhadap variabel dependen. Untuk menguji keberartian regresi multipel pada variabel $\mathrm{X}_{1}$ dan $\mathrm{X}_{2}$ terhadap $\mathrm{Y}$ secara bersama-sama yaitu dengan mencari F Fitung kemudian dibandingkan dengan $F_{\text {tabel. }}$ Rumus uji $\mathrm{F}$ untuk menguji keberartian regresi multipel yaitu sebagai berikut:

$$
F=\frac{\frac{J K_{(\text {Reg) }}}{k}}{\frac{J K_{(S)}}{(n-k-1)}}
$$

(Malhotra, 2012)

Keterangan: $\mathrm{F}=$ Nilai $\mathrm{F}_{\text {hitung; }} \mathrm{JK}_{(\mathrm{Reg})}=$ Nilai Kuadrat Regresi; $\mathrm{JK}_{(\mathrm{S})}=$ Jumlah Kuadrat Sisa (Residual); $\mathrm{k}=$ jumlah prediktor/variabel bebas; $\mathrm{n}=$ jumlah data penelitian

Kesimpulan Fh > Ft, maka keberartian regresi multipel yang diuji adalah signifikan, yaitu dapat diberlakukan ke populasi dengan taraf kesalahan 5\% maupun 1\%. Kriteria pengambilan keputusan untuk hipotesis yang diajukan adalah: (1) Jika $F_{\text {hitung }}>F_{\text {tabel }}$ maka $\mathrm{H}_{0}$ ditolak dan $\mathrm{H}_{\mathrm{a}}$ diterima; (2) Jika $\mathrm{F}_{\text {hitung }} \geq \mathrm{F}_{\text {tabel }}$ maka $\mathrm{H}_{0}$ diterima dan $\mathrm{H}_{\mathrm{a}}$ ditolak. 
Secara statistik, hipotesis yang akan diuji dalam rangka pengambilan keputusan penerimaan atau penolakan hipotesis dapat ditulis sebagai berikut:

a. Hipotesis Simultan

$\mathrm{H}_{0}: \mu=0$, artinya tidak terdapat pengaruh dari kepribadian karyawan $\left(\mathrm{X}_{1}\right)$ dan budaya organisasi $\left(\mathrm{X}_{2}\right)$ terhadap Keterikatan karyawan (emplooyee engagement) $(\mathrm{Y})$.

$\mathrm{H}_{\mathrm{a} .}: \mu \neq 0$, artinya tidak terdapat pengaruh dari kepribadian karyawan $\left(\mathrm{X}_{1}\right)$ dan budaya organisasi $\left(\mathrm{X}_{2}\right)$ terhadap keterikatan karyawan (employee engagement) $(\mathrm{Y})$.

Kemudian, formula yang digunakan untuk menguji keberartian koefisien regresi multipel dari variabel $\mathrm{X}_{1}$ terhadap $\mathrm{Y}$ dan $\mathrm{X}_{2}$ terhadap $\mathrm{Y}$ adalah :

$$
\mathrm{t}=\frac{b_{i}}{S b_{i}} \quad \text { (Malhotra,2012) }
$$

Keterangan: $\mathrm{t}=$ Nilai $\mathrm{t}_{\text {hitung; }} \mathrm{b}_{\mathrm{i}}=$ koefisien regresi $\mathrm{X}_{\mathrm{i}} \mathrm{Sb}_{\mathrm{i}}=$ Kesalahan baku (Standard Error) koefisien regresi $\mathrm{X}_{\mathrm{i}}$;

Kriteria pengambilan keputusan untuk hipotesis yang diajukan adalah: (1) Jika $t_{\text {hitung }}>\mathrm{t}_{\text {tabel }}$ maka $\mathrm{H}_{0}$ ditolak dan $\mathrm{H}_{\mathrm{a}}$ diterima; (2) Jika thitung $\leq t_{\text {tabel }}$ maka $\mathrm{H}_{0}$ diterima dan $\mathrm{H}_{\mathrm{a}}$ ditolak

Taraf kesalahan 0,05 dengan derajat kebebasan dk (n-k-1) pada hipotesis pertama dan kedua (parsial) pada uji dua pihak. Secara statistik, hipotesis yang akan diuji dalam rangka pengambilan keputusan penerimaan atau penolakan hipotesis dapat ditulis sebagai berikut: (1) Hipotesis parsial pertama: $\mathrm{H}_{0}: \mu=0$, artinya tidak terdapat pengaruh dari kepribadian karyawan $\left(\mathrm{X}_{1}\right)$ terhadap keterikatan karyawan (employee engagement) ( $\mathrm{Y}$ ).

$\mathrm{H}_{\mathrm{a}}: \mu \neq 0$, artinya terdapat pengaruh dari kepribadian karyawan $\left(\mathrm{X}_{1}\right)$ terhadap keterikatan karyawan (employee engagement) (Y).

(2) Hipotesis parsial kedua: $\mathrm{H}_{0}: \mu=0$, artinya tidak terdapat pengaruh dari budaya organisai (X2) terhadap keterikatan karyawan (employee engagement) (Y). $\mathrm{H}_{\mathrm{a}}: \mu \neq 0$, artinya terdapat pengaruh dari budaya organisai (X2) terhadap keterikatan karyawan (employee engagement) (Y).

Pada penelitan ini digunakan analisis regresi untuk mengetahui adanya peran antara variabel bebas dan variablinear berganda (multiple regressiel terikat, lebih tepatnya melihat pengaruh antar variabel. Pengolahan data menggunakan program Statistical Packagess for Social Sciences (SPSS) version 20.0 for Windows.

\section{HASIL DAN PEMBAHASAN}

Analisis Deskriptif. Keterikatan karyawan (employee engagement) pada PT. X berada pada kategori tinggi. Tingkat employee engagement pada laki-laki memiliki skor rata-rata lebih tinggi dibandingkan employee engagement pada perempuan. Hal ini dikarenakan laki-laki menjadi sumber keuangan utama bagi keluarganya sehingga berpengaruh terhadap sikap engagement di tempat kerja. Sama halnya dengan hasil penelitian pada sampel di Belgia, Jerman, dan Norwegia bahwa skor tiga dimensi employee engagement (vigor, dedication, dan absorption) laki-laki sedikit lebih tinggi dari perempuan (Schaufeli W.B., Bakker A.B., dan Salanova M,2010)

Hasil penelitian menunjukkan bahwa masa kerja ternyata menentukan tingkat keterikatan karyawan. Karyawan berusia lebih dari 51 tahun dengan masa kerja yang 
lebih lama yaitu lebih dari 16 tahun memiliki tingkat keterikatan karyawan yang lebih tinggi. Hal ini dikarenakan lamanya masa kerja dengan usia mendekati pensiun menunjukkan loyalitas karyawan sehingga karyawan lebih mengenal kondisi perusahaan, lebih engage, dan punya rasa memiliki terhadap organisasi. Hal ini sesuai dengan pendapat Schaufeli W.B., Bakker A.B., dan Salanova M (2010) bahwa keterikatan karyawan sedikit meningkat dengan usia tetapi terdapat hubungan yang lemah diantara keduanya sehingga sangat sulit untuk dipertimbangkan.

Berdasarkan jenis jabatan, hasil analisis menunjukkan bahwa tingkat keterikatan karyawan yang paling rendah berada pada jabatan Staff dan Divisi Produksi dan Operasi sehingga berpengaruh terhadap ketepatan waktu penyelesaian proyek. Namun demikian, terdapat faktor internal dan eksternal lain yang juga dapat mempengaruhi ketepatan waktu penyelesaian proyek, seperti peramalan perusahaan, kebijakan pemerintah, dan lain-lain. Dimensi keterikatan karyawan yang mendapatkan skor paling tinggi adalah dimensi dedikasi sedangkan skor paling rendah berada pada dimensi vigor (semangat kerja). Dedikasi mengacu pada keterlibatan dalam pekerjaan yang ditengarai oleh perasaan bermakna, semangat, inspirasi, bangga, dan tantangan di tempat kerja. Vigor mengacu pada kemauan dan tekad untuk mengerahkan energi dan usaha dalam pekerjaan dan menjadi semangat, ketahanan kerja tinggi, ulet serta gigih ketika menghadapi rintangan. Langkah yang dapat dilakukan untuk memperbaiki vigor yaitu dengan memperbanyak reward kepada karyawan yang aktif di perusahaan dan menciptakan tempat kerja yang nyaman untuk meningkatkan ketahanan kerja karyawan

Hasil analisis terhadap variabel kepribadian karyawan menunjukkan bahwa kepribadian karyawan PT X berada pada kategori tinggi. Dimensi kepribadian yang mendapatkan skor paling tinggi adalah ekstraversi sedangkan skor paling rendah berada pada stabilitas emosi. Dimensi ekstraversi adalah level kenyamanan karyawan dalam membina hubungan sosial sedangkan stabilitas emosi adalah kemampuan seseorang untuk menghadapi stress. Karyawan memiliki kualitas membina hubungan sosial dengan rekan kerja maupun atasan cukup baik namun kurang mampu dalam menghadapi stress kerja. Stress kerja dapat timbul karena beban pekerjaan yang berlebih ataupun tenggat waktu yang tidak tercapai. Skor paling tinggi pada ekstraversi menunjukkan bahwa ekstraversi adalah indikator kepribadian paling berpengaruh terhadap employee engagement. Hasil penelitian ini sejalan dengan hasil penelitian Langelaan S, Bakker AB, van Doornen LJ, dan Schaufeli W (2006) bahwa ekstraversi paling berpengaruh terhadap engagement karyawan. Hal ini dikarenakan ekstraversi merupakan potensi sosial yang mendorong kenyamanan karyawan berinteraksi dengan rekan kerja sehingga meningkatkan engagement karyawan. Perbaikan untuk stabilitas emosi karyawan bisa melalui program pelatihan di lingkungan eksternal perusahaan seperti mengadakan acara rekreasi/outbond untuk merefresh karyawan agar tidak jenuh dengan pekerjaan yang dilakukan. Melalui program yang menurut karyawan menyenangkan akan membantu membuat emosi karyawan cenderung stabil dan meminimalisir stress.

Hasil analisis terhadap variabel budaya organisasi menurut karyawan PT X memiliki kriteria sebagai budaya yang kuat. Karakteristik budaya organisasi yang mendapatkan skor paling tinggi adalah karakteristik orientasi pada hasil sedangkan skor paling rendah berada pada karakteristik inovasi dan pengambilan risiko serta karakteristik keagresifan yang memiliki skor rata-rata yang sama. Orientasi pada hasil adalah tingkat manajemen menitikberatkan pada perolehan atau hasil. Inovasi dan pengambilan risiko adalah tingkat perusahaan dalam mendorong pekerja untuk menjadi inovatif dan berani menghadapi 
risiko. Keagresifan adalah tingkat orang-orang akan menjadi agresif dan kompetitif. Skor orientasi pada hasil yang tinggi menunjukkan bahwa karakteristik budaya orientasi pada hasil (task oriented) PT X paling berpengaruh terhadap employee engagement. Task Oriented pada PT. memperhatikan pekerjaan, penetapan tujuan, rencana yang jelas, fokus terhadap struktur, peran dan tugas, prioritas untuk mencapai hasil yang memuaskan, jadwal ketat, rencana detil, sistem hukum/hadiah. Task oriented mendorong karyawan untuk berkontribusi lebih dan engage terhadap organisasi. Hal ini sesuai dengan penelitian yang dilakukan Inceoglu, Ileke dan Warr, Petter. (2012) bahwa orientasi pada hasil mendorong karyawan untuk lebih engage terhadap pekerjaan dan organisasinya.

Hasil analisis statistik menunjukkan bahwa kepribadian karyawan dan persepsi budaya organisasi secara simultan dan parsial mempengaruhi variabel keterikatan karyawan (employee engagement) pada PT X. Pengaruh yang positif tersebut berarti bahwa setiap terjadi kenaikan indikator variabel kepribadian karyawan dan persepsi budaya organisasi maka akan terjadi pula kenaikan pada keterikatan karyawan. Hasil analisis per variabel manunjukkan bahwa kepribadian karyawan memberikan pengaruh yang lebih besar terhadap keterikatan karyawan jika dibandingkan dengan budaya organisasi. Ini memberikan kesimpulan bahwa faktor internal merupakan faktor yang menjadi langkah awal dan bersifat lebih stabil dalam membentuk dan mempertahankan keterikatan karyawan terhadap organisasi.

Variabel kepribadian karyawan berpengaruh positif dan signifikan terhadap variabel keterikatan karyawan pada PT X. Pengaruh yang positif tersebut berarti bahwa setiap terjadi kenaikan indikator variabel kepribadian karyawan maka akan terjadi pula kenaikan pada keterikatan karyawan. Hal ini sesuai dengan teori Albrecht, Simon L., et al (2015) bahwa keterikatan terjadi jika pekerjaan yang dilakukan sesuai dengan nilai-nilai pribadi, minat, kemampuan, dan kepribadian karyawan. Penelitian serupa telah dilakukan oleh Ongore,Ozgur (2014); Amir F, et.al. (2014); Zaidi,N.R et.al. (2013), Akhtar, R, et.al. (2015:44-49), Bozionelos, Nikos, 2004), Langelaan, S, et. al. (2006) bahwa trait kepribadian lima besar berpengaruh terhadap keterikatan karyawan.

Variabel budaya organisasi berpengaruh positif dan signifikan terhadap variabel keterikatan karyawan pada PT X. Pengaruh yang positif tersebut berarti bahwa setiap terjadi kenaikan variabel budaya organisasi maka akan terjadi pula kenaikan pada keterikatan karyawan. Hasil penelitian ini sejalan dengan hasil penelitian yang dilakukan oleh Robbins, Stephen P \& Judge, Timothy, A. (2015); dan Akbar, M Reza (2013) bahwa karakteristik budaya organisasi berpengaruh terhadap keterikatan karyawan

Analisis Verifikatif. Untuk menguji statitistik pada penelitian ini digunakan pendekatan analisis regresi linear berganda. Data yang digunakan adalah kepribadian karyawan (X1) dan budaya organisasi (X2) sebagai variabel bebas serta keterikatan karyawan (employee engagement) sebagai variabel terikat (Y)

Koefisien Korelasi. Koefisien korelasi (r) menunjukkan derajat korelasi/hubungan antara variabel bebas $\left(\mathrm{X}_{1} \& \mathrm{X}_{2}\right)$ dan variabel terikat $(\mathrm{Y})$. Uji korelasi terhadap ketiga variabel tersebut diolah dengan menggunakan Pearson Correlation dalam SPSS 20.0 for Windows. Berikut hasil analisis korelasi penelitian ini diuraikan pada Tabel 1. sebagai berikut:

Pada Tabel 1, nilai korelasi antara keterikatan karyawan dengan kepribadian karyawan, keterikatan karyawan dengan persepsi budaya organisasi berturut-turut adalah 0,740 dan 0,715. Berdasarkan pedoman interpretasi nilai korelasi, maka nilai korelasi 
0,740 dan 0,715 berada pada interval 0,600-0,799 yang termasuk ke dalam tingkat korelasi yang kuat. Artinya adalah hubungan keterikatan karyawan dengan kepribadian karyawan berada dalam kategori kuat. Demikian halnya dengan hubungan keterikatan karyawan dengan budaya organisasi juga berada dalam kategori kuat.

Tabel 1. Output Korelasi

\begin{tabular}{llrrr}
\multicolumn{5}{c}{ Correlations } \\
\hline & $\begin{array}{c}\text { Employee } \\
\text { Engagement }\end{array}$ & $\begin{array}{c}\text { Kepribadian } \\
\text { Karyawan }\end{array}$ & $\begin{array}{c}\text { Persepsi Budaya } \\
\text { Organisasi }\end{array}$ \\
\hline Pearson & Employee_Engagement & 1.000 & .740 & .715 \\
Correlation & Kepribadian_Karyawan & .740 & 1.000 & .809 \\
& Persepsi_Budaya_ & .715 & .809 & 1.000 \\
& Organisasi & & & .000 \\
Sig. (1-tailed) & Employee_Engagement &. &. & .000 \\
& Kepribadian_Karyawan & .000 & .000 & .000 \\
& Persepsi_Budaya_ & .000 & & 90 \\
& Organisasi & & 90 & 90 \\
& Employee_Engagement & 90 & 90 & 90 \\
& Kepribadian_Karyawan & 90 & 90 & \\
& Persepsi_Budaya_ & 90 & & \\
& Organisasi & & &
\end{tabular}

Regresi Berganda. Penelitian ini terdiri dari dua variabel independen sehingga teknik analisis regresi yang digunakan adalah regresi linier ganda (multiple). Analisis regresi ganda digunakan untuk mengetahui pengaruh dua variabel independen yaitu kepribadian karyawan dan persepsi budaya organisasi terhadap variabel terikat yaitu keterikatan karyawan baik secara simultan maupun parsial.

Dari Tabel 2 diketahui persamaan regresi $\mathrm{Y}=1,281+0,401 \mathrm{X}_{1}+0,244 \mathrm{X}_{2}$.

Pada persamaan tersebut nilai konstanta adalah 1,281, hal tersebut dapat diartikan apabila nilai kepribadian karyawan dan budaya organisasi diasumsikan 0 maka maka besarnya keterikatan karyawan sebesar 1,281. Koefisien regresi pada variabel kepribadian karyawan (X1) adalah 0,401, artinya setiap perubahan satu satuan kepribadian karyawan dengan asumsi budaya organisasi $=0$ maka nilai keterikatan karyawan akan berubah sebesar 0,41. Selanjutnya, koefesien regresi pada variabel budaya organisasi (X2) adalah 0,244, artinya setiap perubahan satu satuan budaya organisasi dengan asumsi kepribadian karyawan $=0$ maka nilai keterikatan karyawan akan berubah sebesar sebesar 0,244.

Tabel 2. Output Koefisien Regresi

\begin{tabular}{|c|c|c|c|c|c|c|}
\hline \multirow{2}{*}{\multicolumn{2}{|c|}{ Model }} & \multicolumn{2}{|c|}{$\begin{array}{c}\text { Unstandardized } \\
\text { Coefficients }\end{array}$} & \multirow{2}{*}{$\begin{array}{c}\text { Standardized } \\
\text { Coefficients }\end{array}$} & \multirow[b]{2}{*}{$\mathrm{t}$} & \multirow[b]{2}{*}{ Sig. } \\
\hline & & $\mathrm{B}$ & Std. Error & & & \\
\hline 1 & (Constant) & 1.281 & 2.579 & & .497 & .621 \\
\hline & Kepribadian Karyawan & .401 & .100 & .468 & 4.000 & .000 \\
\hline & $\begin{array}{l}\text { Persepsi } \\
\text { Budaya Organisasi }\end{array}$ & .244 & .085 & .336 & 2.873 & .005 \\
\hline
\end{tabular}


Untuk mengetahui besar pengaruh dari setiap variable bebas terhadap variabel terikat akan diketahui melalui nilai koefisien determinasi seperti dijelaskan pada Tabel 3.

Tabel 3. Output Koefisien Determinasi

\begin{tabular}{llrrr}
\hline Model & R & R Square & Adjusted R Square & Std. Error of the Estimate \\
\hline 1 & $.766^{\text {a }}$ & .587 & .578 & 3.94571 \\
\hline a. Predictors: (Constant), Persepsi_Budaya_Organisasi, Kepribadian_Karyawan \\
b. Dependent Variable: Employee_Engagement
\end{tabular}

Koefisien determinasi $\left(\mathrm{R}^{2}\right)$ yang dihasilkan adalah 0,587. Artinya, keterikatan karyawan pada PT. X, 58,7\% dipengaruhi oleh kepribadian karyawan dan budaya organisasi. Selanjutnya sisanya $(100 \%-58,7 \%=41,3 \%)$ dipengaruhi oleh faktor-faktor atau variabel lain yang tidak diteliti dalam penelitian ini.

Uji Hipotesis. Untuk menguji keberartian variabel kepribadian karyawan $\left(\mathrm{X}_{1}\right)$ dan budaya organisasi $\left(\mathrm{X}_{2}\right)$ terhadap keterikatan karyawan (employee engagement) (Y) baik secara simultan maupun parsial maka dilakukan uji hipotesis dengan alat uji : uji F (untuk uji simultan) dan uji t (untuk uji parsial). Hasil pengujian secara simultan dapat dilihat padaTabel 4.

Tabel 4. Output Uji F

\begin{tabular}{lrrrrr}
\hline Model & \multicolumn{5}{c}{ Mean } \\
\hline $\begin{array}{l}\text { Regressi } \\
\text { on }\end{array}$ & 1927.760 & 2 & 963.880 & 61.91 & $.000^{\mathrm{a}}$ \\
Residual & 1354.467 & 87 & 15.569 & & \\
$\quad$ Total & 3282.227 & 89 & & & \\
\hline
\end{tabular}

a. Predictors: (Constant), Persepsi_Budaya_Organisasi, Kepribadian_Karyawan

b. Dependent Variable: Employee_Engagement

Melalui uji ANOVA atau uji $\mathrm{F}$ didapat nilai $\mathrm{F}_{\text {hitung }}$ sebesar 61,912 dengan nilai signifikansi 0.00, sedangkan nilai $F_{\text {Tabel }}=1,45$. Nilai $F_{\text {hitung }}>F_{\text {tabel }}(61,912>1,45)$, pada nilai signifikansi 0.00 lebih kecil dari taraf signifikansi yang ditetapkan sebesar 0.05, maka dapat disimpulkan bahwa hipotesis yang menyatakan bahwa terdapat pengaruh kepribadian karyawan $\left(\mathrm{X}_{1}\right)$ dan budaya organisasi $\left(\mathrm{X}_{2}\right)$ terhadap keterikatan karyawan $(\mathrm{Y})$ dapat diterima. Dapat disimpulkan bahwa kepribadian karyawan dan budaya organisasi secara simultan dan signifikan mempengaruhi keterikatan karyawan pada PT X.

Untuk mengetahui pengaruh kepribadian karyawan terhadap employee engagement secara parsial dapat dilihat dari Tabel 5.

Untuk pengujian hipotesis parsial membandingkan $t_{\text {hitung }}$ dengan $t_{\text {tabel }}=1,980$. $t_{\text {hitung }}$ yang dihasilkan untuk variabel kepribadian karyawan adalah 4,000, maka thitung $>t_{\text {tabel }}$ $(4,000>1,980)$, artinya terdapat pengaruh dari kepribadian karyawan $\left(\mathrm{X}_{1}\right)$ terhadap keterikatan karyawan (Y) pada PT X. Nilai probabilitas variabel kepribadian karyawan jauh di bawah 0,05 yaitu 0,000, 
Tabel 5. Output Uji t Kepribadian Karyawan

\begin{tabular}{llrrrrrr}
\hline & & \multicolumn{2}{c}{$\begin{array}{l}\text { Unstandardized } \\
\text { Coefficients }\end{array}$} & \multicolumn{2}{c}{$\begin{array}{c}\text { Standardized } \\
\text { Coefficients }\end{array}$} & & \\
\cline { 2 - 5 } Model & \multicolumn{2}{c}{ B } & Std. Error & Beta & \multicolumn{1}{c}{ t } & \multicolumn{1}{c}{ Sig. } \\
\hline $1 \quad$ (Constant) & 1.281 & 2.579 & & & .497 & .621 \\
& KepribadianKaryawan & .401 & .100 & & .468 & 4.000 & .000 \\
& Persepsi & .244 & .085 & & .336 & 2.873 & .005 \\
& Budaya Organisasi & .24 & & & & & \\
\hline
\end{tabular}

sehingga melalui metode ini ditemukan pula pada tingkat signifikansi 5\% variabel kepribadian karyawan berpengaruh positif dan signifikan terhadap keterikatan karyawan (Y) pada PT X Pada variabel budaya organisasi thitung $>t_{\text {tabel }}(2,873>1,980)$, maka hipotesis terdapat pengaruh dari budaya organisasi $\left(\mathrm{X}_{2}\right)$ terhadap keterikatan karyawan (Y) pada PT. X dapat diterima. Nilai probabilitas variabeli budaya organisasi jauh dibawah 0,05 yaitu 0,005 sehingga melalui metode ini ditemukan pula pada tingkat signifikansi 5\% variabel budaya organisasi berpengaruh positif dan signifikan terhadap variabel keterikatan karyawan (Y) pada PT X.

\section{PENUTUP}

Simpulan. Hasil analisis secara deskriptif terhadap variabel variabel penelitian dapat diidentifikasikan bahwa keterikatan karyawan (employee engagement) berada pada kategori tinggi.Dimensi keterikatan karyawan yang memberikan respon sangat positif dengan perolehan skor tertinggi adalah dimensi dedikasi sedangkan skor paling rendah berada pada dimensi vigor (semangat kerja). Keterlibatan dalam pekerjaan yang ditengarai oleh perasaan bermakna, bangga, dan tantangan di tempat kerja (dedikasi) ternyata tidak serta merta memberikan kemauan dan tekad untuk mengerahkan energi dan usaha dalam menyelesaikan pekerjaan, ketahanan kerja tinggi, serta gigih ketika menghadapi rintangan (vigor). Pada Variabel kepribadian karyawan, secara keseluruhan berada pada kategori baik. Dimensi stabilitas emosi memiliki skor terendah. Disini ada faktor yang harus dimiliki untuk dapat mengatasi kesenjangan ini, salah satu diantaranya adalah peningkatan kompetensi dan peningkatan kemampuan mengatasi stress kerja. Perlu dilakukan pelatihan peningkatan kompetensi dan pelatihan untuk mengatasi stress kerja. Kompetensi yang meningkat akan mendorong karyawan untuk percaya diri dan mengerahkan energi dalam menyelesaikan pekerjaan. Perlu juga dilakukan kegiatan di luar perusahaan seperti mengadakan acara rekreasi/outbond untuk merefresh karyawan agar tidak jenuh dengan pekerjaan yang dilakukan. Melalui program yang menurut karyawan menyenangkan akan membantu membuat emosi karyawan cenderung stabil dan meminimalisir stress.

Budaya organisasi menurut karyawan PT X memiliki kriteria sebagai budaya yang kuat. Karakteristik budaya organisasi yang mendapatkan skor paling tinggi adalah karakteristik orientasi pada hasil sedangkan skor paling rendah berada pada karakteristik inovasi dan pengambilan risiko. Peningkatan skor ini dapat dengan lebih menghargai penyampaian ide/pemikiran/cara baru dari karyawan sehingga karyawan lebih terdorong untuk menjadi inovatif. Kemudian maksimalkan upaya pemberian tugas yang menantang 
dengan target pencapaian yang tinggi dan realistis sesuai kompetensi karyawan untuk meningkatkan budaya pengambilan risiko yang tidak menekan karyawan.

Kepribadian karyawan dan budaya organisasi secara simultan dan parsial mempengaruhi variabel employee engagement pada PT X. Kepribadian karyawan memiliki nilai pengaruh terhadap keterikatan karyawan lebih tinggi jika dibandingkan dengan budaya organisasi

\section{DAFTAR RUJUKAN}

Akbar, Muhammad Rizza. (2013) "Pengaruh Budaya Organisasi terhadap Employee Engagement (Studi pada Karyawan PT. Primatexco Indonesia di Batang)”. Journal of Social and Industrial Psychology. 2 (1) .http://journal.unnes.ac.id/sju/index.php/sip

Akhtar R., Boustani L., Tsivrikos D., dan Premuzic T.C. (2015) “The engageable personality: Personality and trait Emotional Intelligence as predictors of work engagement”. Journal of Personality and Individual Differences. (73): 44-49. http://dx.doi.org/10.1016/j.paid.2014.08.040. www.elsevier.com

Albrecht, Simon L., et al (2015) "Employee engagement, human resource management practices and competitive advantage". Journal of Organizational Effectiveness: People and Performance. 2 (1):7-35. ISSN : 2051-6641. www.emeraldinsight.com.

Amir F., et al (2014) "Measuring the Effect of Five Factor Model of Personality on Team Performance with Moderating Role of employee engagement". Journal of Psychology and Behavioral Science. 2 (2): 221-255, ISSN: 2374-2380.

Bozionelos, Nikos. (2004) "The big five of personality and work involvement". Journal of Managerial Psychology. 19: 69 - 81 Permanent link to this document: http://dx.doi.org/10.1108/02683940410520664

Denison, Daniel R, et al. (2011) "Do consistent corporate cultures have better bisiness performance? Exploring the Interaction Effect”. Human Relation Journal, DOI:10.1177/0018726711426352.hum.sagepub.com

Denison, Daniel R. (2011) “Denison Organizational Culture Survey: Content Modules Employee Engagement.” Tersedia: www.Denison Culture.com yang diakses pada [14 Januari 2016].

Inceoglu, Ileke dan Warr, Petter. (2012) “Personality and Job Engagement”. Journal of Personnel Psychology. 10 (4): 177-181. http://dx.doi.org/10.1027/18665888/a000045

Kreitner and Kinicki. (2014) Perilaku Organisasi. Salemba Empat. Jakarta

Langelaan S, Bakker AB, van Doornen LJ, dan Schaufeli W (2006) "Burnout and work engagement: Do individual differences make a difference?”. Journal Personality Individual Differences. (40): 521-532. http://dx.doi.org/10.1016/j.paid.2014.08.040. www.elsevier.com

Malhotra, Naresh K. (2012) Marketing Research: An Applied Approach, Fourth Ed. FT Press

Markos, Solomon dan Sridevi, M Sandhya (2010) "Employee Engagement: The Key to Improving Performance”, International Journal of Bussiness and Management. 5 (12) December 2010, ISSN 2321 - 8916 
Naidoo, Pervashnee \& Martins, Nico. (2014) "Investigating the relationship between organizational culture and work engagement”. Journal of Problems and Perspectives in Management., 12 (4), ISSN 172 -7 7051

Ongore, Ozgur. (2014) “A Study Of Relationship Between Personality Traits And Job Engagement”. Procedia Social and Behavioral Sciences. 141: 1315-1319., http://dx.doi.org/10.1016/j.sbspro.2014.05.226, www.elsevier.com

Parent, J. D., \& Lovelace, K. J. (2015) “The Impact of Employee Engagement and a Positive Organizational Culture on an Individual's Ability to Adapt to Organization Change”. Eastern Academy of Management Proceedings”, Journal of Organization Behavior and Theory Track. 1-20. Available at: http://scholarworks.merrimack.edu/mgt_facpub/10

Robbins, Stephen P \& Judge, Timothy, A. (2015) Perilaku Organisasi. Jakarta: Salemba Empat.

Schaufeli W.B., Bakker A.B., dan Salanova M. (2010) "The Measurement of Work Engagement With a Short Questionnaire A Cross-National Study.” Educational and Psychological Measurement. 66 (4): 701-716.

Suharti \& Suliyanto. (2012) "The Effects of Organizational Culture and Leadership Style toward Employee Engagement and Their Impacts toward Employee Loyalty". World Review of Business Research., 2 (5): 128-139, ISSN :1838-3955

Team FME. (2015) “Preparing for Personality Tests Career Skills.” Tersedia: www.freemanagement-ebooks.com yang diakses pada 13 Januari 2016.

Wildermuth, Chris, (2005) The Effect of Personality on International Assignment Success, www.worlwideerc.org

Zaidi, N.R., Wajid, R.A., Zaidi, R.B., Zaidi, G.B. and Zaidi, M.T. (2013). "The big five personality traits and their relationship with work engagement among public sector university teachers of Lahore”. African Journal of Business Management. 7 (15): 1344-1353, ISSN 1993-8233,.DOI: 10.5897/AJBM12.290, 